\title{
La conciliación procesal obligatoria como mecanismo de descongestión judicial.
}

\author{
Análisis en la Jurisdicción Contenciosa Administrativa de Antioquia, \\ Bolívar, Cundinamarca y Valle del Cauca* \\ Compulsory procedural conciliation as a mechanism for judicial \\ decongestion.
}

Analysis in the Contentious-Administrative Jurisdiction of Antioquia, Bolivar, Cundinamarca and Valle del Cauca

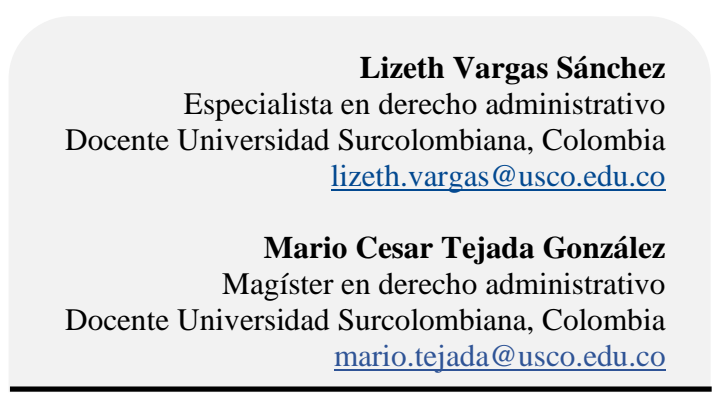

Recibido: 09/10/2018 Aprobado 21/12/2018

DOI: $10.25054 / 16576799.2341$

\section{RESUMEN}

El presente artículo analiza la pertinencia que ha tenido la Audiencia de Conciliación Obligatoria que consagran los artículos 70 de la Ley 1395 de 2010 y el inciso $4^{\circ}$ del artículo 192 de la Ley 1437 de 2011 dentro los procesos de reparación directa en la Jurisdicción Contenciosa Administrativa de los departamentos de Antioquia, Bolívar, Cundinamarca y Valle del Cauca desde el año 2011 al 2018 como medida de descongestión judicial. Con ese propósito, se plantearon objetivos que condujeron a la conclusión de esta investigación. En primer lugar, se realizó la identificación de los procesos de reparación directa de primera instancia en los cuales se profirieron fallos condenatorios en las jurisdicciones y el periodo anteriormente señalado. En segundo lugar, se examinaron dichos procesos para identificar y analizar los factores que incidieron en el desarrollo de la audiencia de conciliación.

Finalmente, se determinó el impacto que tuvo esta audiencia en materia de descongestión judicial. Así, se establecieron los diversos beneficios jurídicos y económicos que trajeron consigo los acuerdos conciliatorios a los que se llegaron en los procesos analizados en la fase final. Los resultados obtenidos se lograron a través de la aplicación de la metodología cuantitativa descriptiva, la cual condujo a concluir que sí es pertinente la audiencia de conciliación judicial como medida de descongestión en las jurisdicciones objeto de estudio en los años 2011 a 2018

\section{PALABRAS CLAVE}

Acción de Reparación Directa; Audiencia de Conciliación Judicial; Jurisdicción Contenciosa Administrativa; Recurso de Apelación.

\footnotetext{
*Artículo de investigación

El presente artículo tiene su origen en los resultados de la investigación denominada "La Conciliación Procesal Obligatoria como Mecanismo de Descongestión Judicial en la Jurisdicción Contenciosa Administrativa de Antioquia, Bolívar, Cundinamarca y Valle del Cauca" realizada por el semillero de investigación Ratio Iuris adscrito al grupo de Investigación CONCIENCIA JURİDICA, siendo auxiliares de investigación las estudiantes Lina Marcela Trujillo Torres, Nathalia Ana Maria Rivera Perdomo, Diana Maria Charry Jimenez y Maria Natalia Castro Leon
} 


\section{ABSTRACT}

This article analyzes the appropriateness of the Mandatory Conciliation Hearing stated in the article 70, Law 1395/2010 and the subsection 4 in the article 192, Law 1437/2011 within the processes of direct reparation of damages through Contentious Administrative Jurisdiction of Antioquia, Bolívar, Cundinamarca and Valle del Cauca from 2011 to 2018 as a measure of judicial decongestion. In order to do th, some objectiv es were set which led to the conclusion of this research. First, the identification of the direct reparation processes of first instance, in which convictions were made in the jurisdictions and the period previously mentioned was carried out. Next, these cases were examined to identify and analyze which factors influenced the development of the Conciliation Hearing.

Finally, the impact that this hearing had on judicial decongestion was determined. Thus, the various legal and economic benefits of the conciliation agreements reached in the processes analyzed in the final phase were established. The results obtained were achieved through the application of the descriptive quantitative methodology, which led to conclude that the Judicial Conciliation Hearing is pertinent as a judicial decongestion method in the jurisdictions under study from 2011 to 2018.

\section{KEYWORDS}

Direct Repair Action; Judicial Conciliation Hearing; Administrative Courts; Appeal

\section{INTRODUCCIÓN}

La administración de justicia, tal como ha sido consagrada por la Constitución de 1991 en el artículo 228 y, según aduce la honorable Corte Constitucional en una cantidad copiosa de sentencias, tiene carácter de derecho fundamental por la íntima relación que comparte con el derecho al debido proceso. Este último, no solamente comprende el acceso del conflicto jurídico a los anaqueles judiciales, sino un pronunciamiento emanado por la autoridad competente, quien debe resolver cabalmente la litis en un término razonable.

No obstante, a pesar del tratamiento garantista que el Estado le ha brindado a la administración de justicia y a la tutela judicial efectiva, la resolución de conflictos se ha visto ralentizada por un fenómeno jurídico denominado "congestión judicial". Este ha surgido, entre otras cosas, por la profusa cantidad de demandas que han ingresado a los juzgados y tribunales cada año, aunado a la creación de acciones constitucionales a partir de 1991, que implica la existencia de más asuntos por resolver.

Por corolario, con el propósito de mitigar la congestión judicial, desde hace algunas décadas se instauró la obligación de celebrar la audiencia de conciliación extrajudicial como requisito de procedibilidad en varios tipos de procesos, incluyendo los medios de control de la jurisdicción contenciosa administrativa; caso en el cual la audiencia debe ser presidida por la Procuraduría
General de la Nación. De manera análoga, gracias al artículo 70 de la Ley 1395 del 2010, y al posterior desarrollo del inciso $4^{\circ}$ del artículo 192 de la Ley 1437 del 2011, se creó una nueva forma de conciliación judicial: al interponerse el recurso de apelación contra la sentencia que condena a la entidad pública, debe celebrarse una audiencia de conciliación para que el juez o magistrado pueda decidir sobre la concesión del recurso.

Con la investigación adelantada, se pretendió establecer si la conciliación judicial que establece la normativa señalada mitigó de forma efectiva la congestión en los despachos judiciales de la jurisdicción contenciosa administrativa, acercando la justicia a la ciudadanía y promoviendo la celeridad entre la misma. Además, se quiso identificar los beneficios jurídicos, económicos y sociales que genera el acuerdo conciliatorio pactado entre la entidad y el demandante. De esta manera, la incógnita que se resolvió fue:

$¿$ ¿Ha sido pertinente, como medida de descongestión judicial, la audiencia de conciliación obligatoria de la que tratan los artículos 70 de la Ley 1395 de 2010 y el inciso $4^{\circ}$ del artículo 192 de la Ley 1437 de 2011 en la Jurisdicción Contenciosa Administrativa de los departamentos de Antioquia, Bolívar, Cundinamarca y Valle del Cauca desde el año 2011 al 2018 dentro los procesos de reparación directa?

Ahora bien, conforme a la problemática abordada, se consideró que la orientación epistemológica más eficaz era la metodología cuantitativa descriptiva, debido a que permitía la descripción, registro, 
cuantificación, análisis e interpretación cabal de todos los datos obtenidos en la revisión de procesos.

Asimismo, para el desarrollo exitoso de la investigación, se analizaron de manera detallada 309 procesos de reparación directa con sentencia condenatoria, proferidas desde el 2011 hasta el 2018, en los que se había convocado a la audiencia de conciliación tratada en el artículo 70 de la Ley 1395 del 2010 y el inciso $4^{\circ}$ del artículo 192 de la Ley 1437 del 2011, pertenecientes a la jurisdicción contenciosa administrativa de los departamentos de Antioquia, Bolívar, Cundinamarca y Valle del Cauca.

Adicionalmente, para asegurar la obtención de resultados certeros y fidedignos, se contó con la colaboración y disposición de las auxiliares de investigación en el proceso de recolección, descripción, tabulación, análisis e interpretación de datos y, como apoyo logístico, se hizo uso de elementos de alta tecnología.

\section{DESARROLLO DEL TEMA}

En primer lugar, es pertinente resaltar que la justicia colombiana es catalogada como: "la sexta más lenta del mundo", ocupando esta posición dentro de ciento ochenta y tres países de acuerdo con los datos del Banco Mundial informe Doing Business del año 2012 (Sánchez, 2014). Por tal motivo, pretendía encontrar la pertinencia de la audiencia de conciliación contemplada en los artículos 70 de la Ley 1395 de 2010 y el inciso $4^{\circ}$ del artículo 192 de la Ley 1437 de 2011 en la Jurisdicción Contenciosa Administrativa en los departamentos Antioquia, Bolívar, Cundinamarca y Valle del Cauca desde el 2011 al 2018 en los procesos de reparación directa, con el fin de verificar si se cumplió el objetivo por el cual fue creada, esto es, para contribuir a la descongestión judicial.

Frente a esta problemática, se estudiaron los diferentes factores por los cuales el demandante, demandado o ambas partes, acuden a la jurisdicción de lo contencioso administrativo, cumpliendo o no con las características de la conciliación y generando implícitamente que su proceso sea ágil o demasiado lento en los mencionados distritos judiciales.

Como primera medida, según Confucio, en China "los conflictos se solucionaban a través de la persuasión moral y el acuerdo, y no bajo coacción" (Confucio, 550 A.C., citado por Osorio-Villegas, 2002), es decir, que la violencia y la fuerza no eran llamadas al momento de resolver una controversia, sino que, por el contrario, lo esencial era la búsqueda de un acuerdo entre las partes en conflicto. Es de esta manera como todavía hoy, en el siglo XXI, se puede observar que existen comités populares en dicha región, cuyo objetivo es ejercer la conciliación y buscar de esta manera la resolución de sus desavenencias de forma pacífica.

Seguidamente, se destaca el continente africano, donde las controversias eran inicialmente solucionadas de manera informal, pues la misma se hacía con una "junta de vecinos", en la cual las personas líderes y cabezas de familia dialogaban directamente con las partes para buscar una solución a su controversia, es decir, en esta región también se evidenció la conciliación como mecanismo directo a la hora de resolver un conflicto.

En el caso griego y romano, la conciliación tuvo un abundante auge, en la medida en que fueron estas regiones en donde se presentó por primera vez "la transacción", que era una forma de resolución de conflictos, la cual era llevada a cabo por los "testemontes, mandaderos de paz y avenidores" (Osorio-Villegas, 2002), quienes se encargaban de analizar la causa objeto del conflicto en cuestión, para de esta manera llegar a un acuerdo entre las partes por vía de transacción, resolviendo de esta manera su controversia.

En los países latinoamericanos, han tomado especial conciencia en fortalecer los mecanismos alternativos de resolución de conflictos, mediante el desarrollo de normatividad en cada uno de sus ordenamientos jurídicos, que busquen y garanticen la armonía de sus asociados.

En el Estado colombiano, la conciliación como mecanismo alternativo ya existía antes de la Constitución de 1991, y para tal efecto, ya había centros de conciliación (v.g. universidades), que permitían a los particulares ejercer estas funciones. No obstante, el tema empezó a tomar forma a partir de la Constitución del 91 tal como lo afirma el artículo 116 de la misma.

De manera análoga, el Congreso de la República, a través de la Ley 23 de 1991, creó mecanismos para descongestionar los despachos judiciales y dictó diversas disposiciones en lo relativo a los centros 
de conciliación como instituciones alternativas, por medio de las cuales se puede acudir tratando de buscar un arreglo a las diferentes y sucintas controversias.

En el caso del derecho civil colombiano, el tema de la conciliación se encuentra latente desde la expedición de la Ley 13 de 1825, siendo la primera en tratar el tema de la conciliación. Esta ley afirma: “...ningún proceso contencioso civil se tramitará sin previamente se haya intentado el medio de conciliación ante uno de los alcaldes municipales o parroquiales" (Peña-Guevara, Polo-García y Solano-Vargas, s.f.).

Ahora bien, en el ámbito del derecho laboral, se encuentra la Ley 120 de 1921 y el Decreto 2158 de 1949 para la resolución de conflictos jurídicos de tipo colectivo e individual respectivamente.

El Congreso de la República, desarrolló la Ley 640 de 2001, a través de la cual reglamentó de manera exclusiva la conciliación como mecanismo alternativo para la solución pacífica de conflictos. Allí se hace referencia a los principios que rigen un acuerdo conciliatorio, las clases de conciliación, cuándo se está frente a un conciliador, quiénes están autorizados para realizar un acuerdo conciliatorio $\mathrm{y}$, específicamente, las diferentes áreas del derecho en las cuales es viable realizar una audiencia de conciliación.

Cabe mencionar, que dentro de esta ley se establecen las principales características de la conciliación entre las cuales se encuentra: solemne, bilateral, onerosa, conmutativa, de libre discusión y acto nominado (CNC, s.f.).

Sin embargo, surge un nuevo interrogante acerca de cuántas clases de conciliación existen en Colombia en materia contenciosa administrativa: como primera medida, se encuentra la conciliación judicial, la cual es llevada a cabo dentro de un proceso judicial, donde la misma está en cabeza del juez quien, en una etapa procesal, tiene la potestad de dialogar directamente con las partes, buscando de esta forma la resolución del conflicto y evitando la continuidad de este. Dentro de la conciliación judicial, se pueden identificar dos momentos para su realización:

El primero de ellos se presenta al comienzo del proceso, en donde las partes son citadas por a una audiencia denominada "audiencia de conciliación". Las partes, en contienda, y el ministerio publico toman lugar en la sala de audiencia, a la hora y fecha asignada por el juzgado, llevando consigo una propuesta de conciliación que, en caso de ser aceptada por las partes, deberá ser aprobada por el juez, quien verificará que se haya hecho de forma legal, respetando los derechos de cada parte en cuestión (MINJUSTICIA, 2015).

El segundo momento es la conciliación judicial previa a la admisión del recurso de apelación de la sentencia condenatoria. Esta conciliación también se encuentra en cabeza del juez como director del proceso judicial. Inicialmente, fue incorporada al anterior Código Contencioso administrativo Decreto 01 de 1984 a través del artículo 70 de la ley 1395 de 2010, adicionado como inciso $4^{\circ}$ del artículo 43 de la Ley 640 de 2001 de la siguiente manera:

Artículo 70. Derogado por el artículo 309 de la Ley 1437 de 2011. Adiciónese un cuarto inciso al artículo 43 de la Ley 640 de 2001, cuyo texto será el siguiente:

En materia de lo contencioso administrativo, cuando el fallo de primera instancia sea de carácter condenatorio y contra el mismo se interponga el recurso de apelación, el juez o magistrado deberá citar a audiencia de conciliación, que deberá celebrarse antes de resolver sobre la concesión del recurso. La asistencia a esta audiencia será obligatoria.

Parágrafo. Si el apelante no asiste a la audiencia, se declarará desierto el recurso (Art. 70. L. 640/2001).

Posteriormente, la Ley 1437 de 2011, nuevo Código Contencioso Administrativo y de lo Contencioso Administrativo -CPACA-, consagró un nuevo procedimiento Contencioso Administrativo con mayor influencia en el sistema de oralidad. Dentro de las etapas del nuevo procedimiento Contencioso Administrativo está (i) la primera, que va desde la presentación de la demanda hasta la audiencia inicial, (ii) desde la finalización de la anterior hasta la culminación de la audiencia de pruebas y (iii) desde la terminación de la anterior, comprende la audiencia de alegaciones y juzgamiento y culmina con la notificación de la sentencia.

En la primera etapa se encuentra la audiencia inicial definida en el artículo 180 numeral 8 del CPACA. Allí se consagra la posibilidad de conciliar las pretensiones de la demanda en cualquier etapa del desarrollo de la audiencia. 
Por su parte, el CPACA estableció otra posibilidad de conciliación dentro del procedimiento Contencioso Administrativo: una vez dictado el fallo en contra de los intereses de la entidad estatal y como requisito de procedibilidad para admisión del recurso de apelación se la sentencia contraria a sus pretensiones. De manera expresa señala el inciso 4 del artículo 192, que obligatoriamente el juez o magistrado debe citar a audiencia de conciliación, la cual deberá celebrarse antes de resolver sobre la concesión del recurso.

El artículo ibídem aduce:

Cuando el fallo de primera instancia sea de carácter condenatorio y contra el mismo se interponga el recurso de apelación, el Juez o Magistrado deberá citar a audiencia de conciliación, que deberá celebrarse antes de resolver sobre la concesión del recurso. La asistencia a esta audiencia será obligatoria. Si el apelante no asiste a la audiencia, se declarará desierto el recurso (Art. 192. L. 1437/2011).

Así las cosas, existen dos momentos dentro del procedimiento contencioso administrativo para hacer uso de la conciliación judicial como mecanismo alternativo de solución de conflictos: la primera se encuentra establecida en el desarrollo de la audiencia inicial -Articulo 180 numeral 8-, y la segunda, una vez se profiera sentencia condenatoria y se presente recurso de apelación, siendo obligatorio convocar audiencia de conciliación como requisito sine quo non para la concesión del recurso de apelación.

El experto en análisis y resolución de conflictos, Harbey Peña Sandoval en su texto 20 años del sistema nacional de conciliación en Colombia: breve análisis normativo, destaca la evolución de la conciliación a lo largo del tiempo, afirmando que en un comienzo la misma era mucho más compleja, contrario de lo que es hoy en día, debido a que ahora es un procedimiento sencillo, organizado y muy técnico que tiene tres pilares fundamentales: "autonomía de la voluntad de las partes, informalidad y flexibilidad" (Peña-Sandoval, 2014). Lo anterior, teniendo en cuenta que son las partes quienes, de mutuo acuerdo, deciden la suerte de su conflicto; por eso es importante destacar que son las partes involucradas el pilar fundamental dentro de una conciliación, pues son solo estas quienes deciden y argumentan el camino a recorrer.
El artículo 3 de la Ley 640 de 2001, ha especificado que es la conciliación extrajudicial la que se realiza antes o por fuera de un proceso judicial; allí las partes resuelven de manera pacífica los conflictos sin necesidad de llegar hasta un juicio.

Además, ha destacado que la conciliación extrajudicial puede ser en derecho o en equidad. Podemos decir que existe una conciliación extrajudicial en derecho cuando esta es realizada en un centro de conciliación o ante autoridades administrativas en cumplimiento de las funciones conciliatorias. La conciliación extrajudicial en equidad es aquella que se realiza ante los conciliadores en equidad, es decir, un líder elegido por la comunidad en razón del reconocimiento, de las capacidades y cualidades, para que actúe como facilitador en la solución de conflictos particulares y comunitarios con base en el sentido de la igualdad, la justicia natural y el beneficio común (MINJUSTICIA, 2015).

La conciliación extrajudicial en materia Contenciosa Administrativa se encuentra reglamentada en el capítulo V de la Ley 640 de 2001. Allí el legislador estableció una competencia exclusiva, en cabeza de los agentes del Ministerio Publico, para conocer las conciliaciones extrajudiciales en materia contenciosa administrativa. Posteriormente, el artículo 13 de la Ley 1285 de 2009 la implementó como requisito de procedibilidad, siendo regulada por el Decreto 1716 de 2009.

De lo anterior se puede inferir que: 1) cualquier ciudadano, sea rico o de escasos recursos, podrá acudir a la justicia haciendo uso del mecanismo de solución de conflictos denominado 'conciliación', la cual se puede realizar a través de apoderado judicial (abogado), o actuando en nombre propio, para que una persona especializada en el tema del conflicto trate de resolverlo en buenos términos; estos terceros podrán ser el juez o el conciliador; 2) como consecuencia de lo anterior, una vez la controversia es conciliada, se logrará la descongestión judicial, objetivo principal de la conciliación y, por otra parte, garantizará la paz y la armonía de todos los asociados que se ven envueltos en la Litis.

De conformidad con la sentencia C-902 de 2008, siendo magistrado ponente Nelson Pinilla Pinilla, la conciliación se ha entendido como:

Un mecanismo alternativo para la solución de conflictos, por cuyo medio las partes, con la 
ayuda de un tercero neutral, calificado y autorizado para ello, resuelven directamente un asunto en que se presenta desacuerdo y que es susceptible de ser conciliable (CConst, C902/2008).

En el texto la eficacia de la audiencia del artículo 70 de la ley 1395 de 2010, publicado en el año 2012 por los Abogados de la Universidad Agraria y estudiantes de la Especialización en Derecho Administrativo de la Universidad Militar Nueva Granada de Colombia, el Doctor Bruno Edwin Toscano López y Cesar Mauricio Ortiz afirman que los procesos contencioso administrativos son costosos y prolongados, tanto para el particular, como para el Estado, que muchas veces ve afectado su presupuesto, pues resulta condenado a pagar cifras millonarias que conllevan a un detrimento del erario del Estado. Es por esta razón, que destaca el autor que es importante tener en cuenta la conciliación para la solución de la controversia, evitando de esta forma el desgaste procesal, económico y la congestión judicial (ToscanoLópez y Ortiz-Ortiz, 2012).

Ahora bien, los seres humanos somos expertos en criticar, y la justicia colombiana no está exenta de ser juzgada; por eso, surgen a diario cuestionamientos sobre la poca agilidad dentro de la rama jurisdiccional, la justicia tardía, procesos eternos y demoras procesales que parecen no tener fin. El magistrado Leonardo Augusto Torres Calderón, en su investigación "reflexiones sobre la congestión judicial en la jurisdicción de lo contencioso administrativo colombiana" ha destacado lo siguiente:

La situación de congestión judicial se ha vuelto tan aguda en la jurisdicción contenciosa administrativa, que medio en broma y medio en serio, los apoderados han llegado a decir que "la vida útil de un abogado es de sólo dos procesos ordinarios", que tienen una duración promedio, en las dos instancias, de 6 a 14 años (TorresCalderón, 2016).

Es decir, es la falta de ánimo conciliatorio en presencia de un conflicto lo que impide la agilidad dentro del aparato judicial, pues al no haber un arreglo directo, las partes continúan en un proceso que en muchos casos se vuelve dilatorio y congestiona el aparato judicial.

Por lo anterior, el autor considera que una solución a este problema de congestión judicial es la creación de nuevos juzgados administrativos que permitan ayudar a la resolución de procesos que actualmente se encuentran tanto en los juzgados administrativos, como el Tribunal Contencioso o, en su defecto, en el Consejo de Estado. Sin embargo, como destaca el autor, no hay presupuesto suficiente para la creación actual de estos despachos adicionales; por ende, se debe resaltar a cada asociado la importancia de conciliar los conflictos, pues de esta manera se logra la justicia pronta y eficaz que es deseada en el ordenamiento jurídico colombiano.

Ante el panorama desolador de la justicia contenciosa administrativa en Colombia en lo relativo a los tiempos de resolución de los medios de control, surge la expectativa de la eficacia de la conciliación como mecanismo de descongestión, en especial cuando ya existe un fallo de primera instancia de carácter condenatorio en contra de las entidades públicas. Como hipótesis inicial se consideró que este este tipo de conciliación postfallo estaba llamado a fracasar, debido a que ya existía un primer pronunciamiento judicial condenatorio; sin embargo, los resultados que arrojó la investigación fueron totalmente diferentes.

A efectos de tener un panorama general de la aplicación del mecanismo en gran parte del país, se escogieron los tribunales de diferentes zonas geográficas; esto es, zona centro con el Tribunal de Antioquia, zona occidente con el Tribunal del Valle del Cauca, zona norte con el Tribunal de Bolívar y la capital del país con el Tribunal Contencioso de Cundinamarca; este último con el mayor cúmulo de trabajo de todos los tribunales.

\section{RESULTADOS Y DISCUSIÓN}

En el desarrollo de esta investigación se logró la revisión de una muestra significativa (15\%) del universo de procesos objeto de estudio en lo que compete a la audiencia de conciliación obligatoria en la Jurisdicción Contenciosa Administrativa en los departamentos de Antioquia, Bolívar, Cundinamarca y Valle del Cauca, como medida de descongestión judicial. Se analizaron de manera exhaustiva 309 procesos de los cuales 142 fueron tramitados por el sistema escritural y 166 mediante audiencias, para la obtención de los resultados mostrados a continuación, en los cuales se han reunido todas las jurisdicciones. Es pertinente aclarar que, por razones de extensión máxima de este artículo, no es posible exhibir las gráficas de cada una de las jurisdicciones. 
Gráfica no. 1. Recurso contra el fallo condenatorio

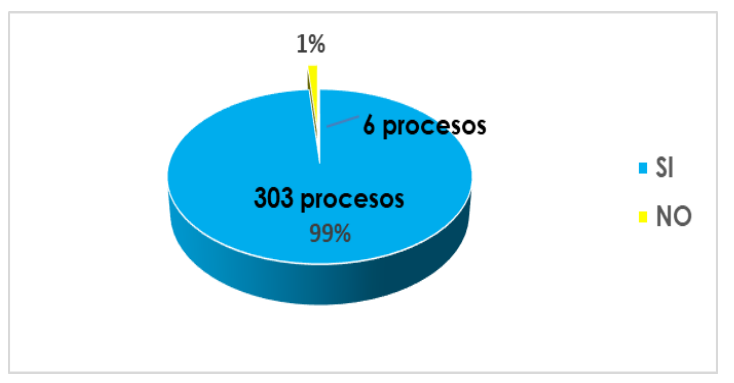

Fuente: Construcción propia

De la gráfica No. 1, se concluye que de los 309 procesos condenatorios de reparación directa de la jurisdicción contencioso-administrativa de cada uno de los departamentos en los que se llevó a cabo esta investigación, en 303 procesos se interpuso recurso de apelación contra el fallo y en 6 procesos, equivalentes a un $1 \%$ no se apeló el fallo.

\section{Gráfica no. 2. Calidad del apelante}

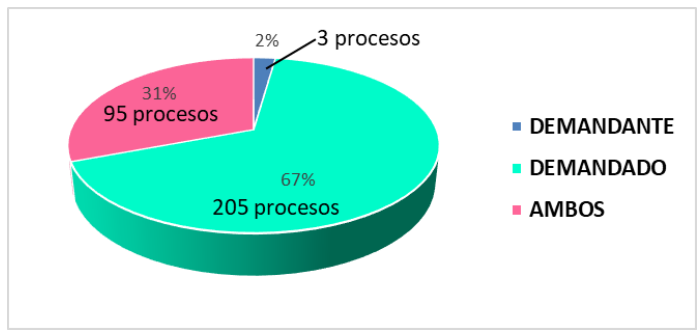

De acuerdo con esta gráfica, de los 303 procesos condenatorios de reparación directa de la jurisdicción contenciosa administrativa de Antioquia, Valle del Cauca, Bolívar y Cundinamarca que fueron apelados, en 205 procesos el apelante era el demandado, en 95 procesos ambas partes apelaron el fallo y en 3 procesos fue el demandante quien apeló el fallo.

\section{Gráfica no. 3. Admisión del recurso}

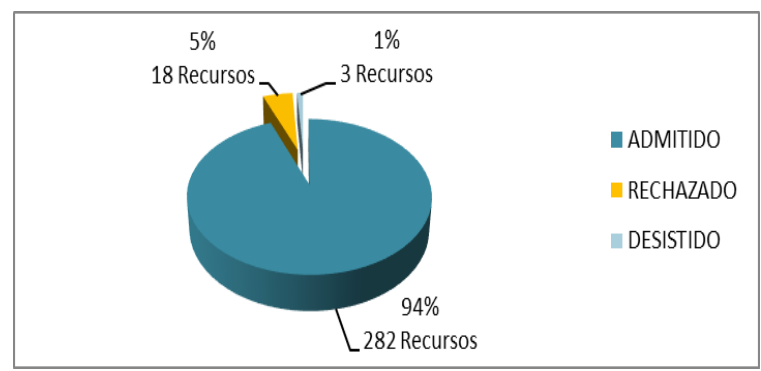

\section{Fuente: Construcción propia}

Como se aprecia en la gráfica No. 3, de los 303 procesos condenatorios de reparación directa de la jurisdicción contencioso administrativa de los departamentos objeto de estudio, en los cuales se interpuso recurso de apelación, en el $94 \%$ de los casos equivalentes a 282 procesos, este fue admitido. En contraste, en 18 procesos, equivalentes a un $5 \%$, el recurso fue rechazado y en 3 procesos hubo desistimiento del recurso, lo que equivale al $1 \%$.

\section{Gráfica no. 4. Motivo de rechazo}

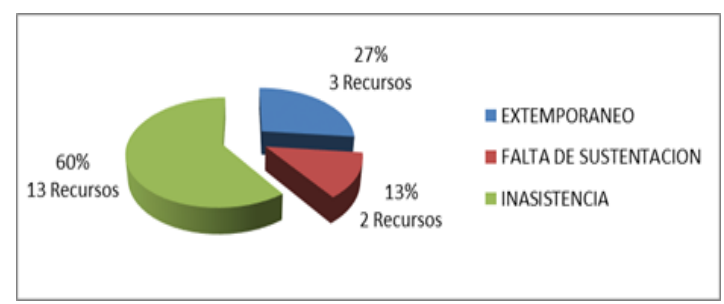

La conclusión a la que se puede llegar con esta gráfica, es que de los 18 procesos condenatorios de reparación directa de las jurisdicciones en las que se llevó a cabo esta investigación, en donde fue rechazado el recurso de apelación, en 13 procesos fue debido a la inasistencia del apelante a la audiencia de conciliación, equivalente al $60 \%$, en 3 procesos el recurso se rechazó por ser radicado por fuera del término legal, es decir, en $27 \%$ y en 2 procesos el apelante no presento los argumentos del recurso en un $15 \%$.

Gráfica no. 5. Asistencia a la audiencia de conciliación del demandante apelante

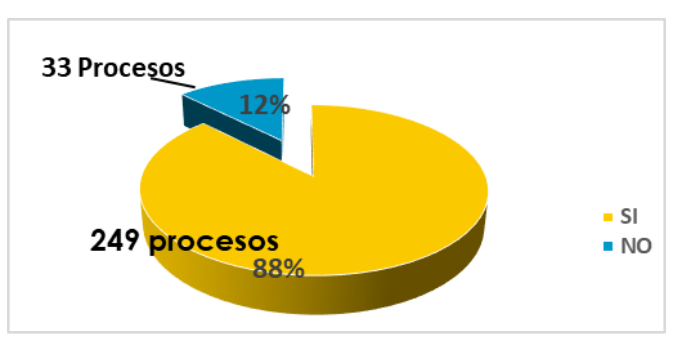

De esta gráfica se concluye que de los 282 procesos condenatorios de reparación directa de las jurisdicciones contenciosas administrativas de Antioquia, valle del cauca, Bolívar y 
Cundinamarca que fueron analizados dentro del periodo de tiempo escogido, en los cuales fue admitido el recurso de apelación, fijando fecha de audiencia de Conciliación, el demandante asistió en el 88\% de los casos; esto es 249 procesos y, en 33 procesos, equivalentes al $12 \%$ no asistió.

Grafica no. 6. Asistencia a la audiencia de conciliación del demandado apelante

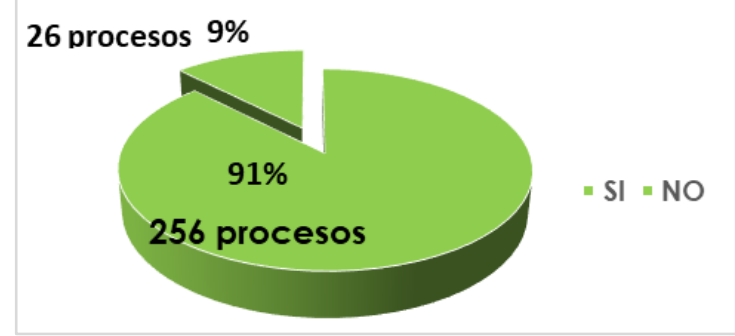

Como se logra advertir con esta gráfica, de los 282 procesos condenatorios de reparación directa de la jurisdicción contencioso-administrativa de Antioquia, Valle del cauca, Bolívar y Cundinamarca que fueron analizados, y en los cuales fue admitido el recurso de apelación, fijando fecha de audiencia de Conciliación, el demandado apelante asistió en el $91 \%$ de los casos esto es 256 procesos y en 26 procesos equivalentes al $9 \%$ no asistió.

Gráfica no. 7. Ánimo conciliatorio del demandante

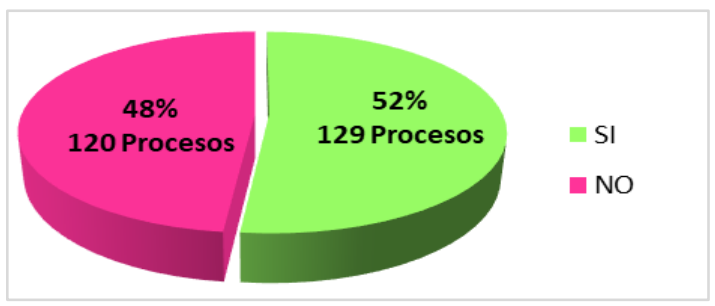

De la gráfica No. 7 se concluye que de los 249 procesos condenatorios de reparación directa de las jurisdicciones contencioso-administrativas ya indicadas, en donde compareció el demandante a audiencia de conciliación entre los años 2011 y 2018, en el 52\% de los casos, esto es, en 129 procesos, el demandante tuvo ánimo conciliatorio, y en el $48 \%$ de los casos, esto es 120 procesos, el demandante no tuvo ánimo conciliatorio.

Gráfica no. 8. Ánimo conciliatorio del demandado

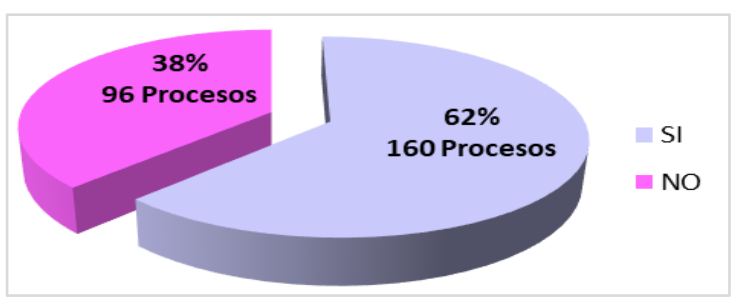

Fuente: Construcción propia

Se observa en esta gráfica que de los 256 procesos condenatorios de reparación directa de la jurisdicción contencioso-administrativa de Antioquia, Valle del cauca, Bolívar y Cundinamarca, en donde compareció el demandando a audiencia de conciliación entre los años 2011 y 2018, en el $62 \%$ de los casos esto es 160 procesos, el demandado tuvo animo conciliatorio, y en el $38 \%$ de los casos, esto es 96 procesos, el demandado no tuvo ánimo conciliatorio.

Gráfica no. 9. Existencia concepto comité de conciliación

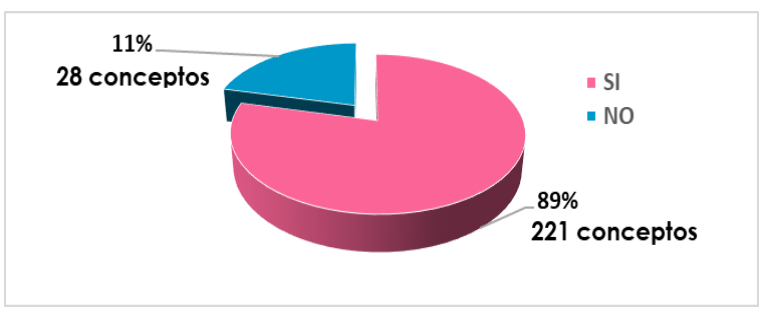

De la anterior grafica se concluye que de los 249 procesos condenatorios de reparación directa de la jurisdicciones contencioso administrativas mencionadas que fueron citados a audiencia de conciliación, en donde compareció el demandando a audiencia de conciliación entre los años 2011 y 2018, en el $89 \%$ de los casos esto es 221 procesos el demandado tenía un concepto del comité de conciliación de la entidad, y en el 11\% de los casos, esto es 28 procesos, el demandado no presentó concepto de comité de conciliación.

Gráfica no. 10. Sentido del concepto comité de conciliación



- FAVORABLE

DESFAVORABLE

- PARCIALMENTE

FAVORABLE

Como muestra la gráfica No. 10, de los 221 procesos condenatorios de reparación directa de la jurisdicción contencioso administrativa de Antioquia, Valle del Cauca, Bolívar y Cundinamarca en que las entidades demandadas asistieron a la audiencia de conciliación y aportaron concepto del comité de conciliación entre los años 
2011 y 2018, en 100 casos (53\%) los conceptos eran favorables. En 72 procesos $(26 \%)$ fue desfavorable, y en 49 procesos $(21 \%)$, el concepto fue parcialmente favorable.

\section{Gráfica no. 11. Acuerdo conciliatorio}

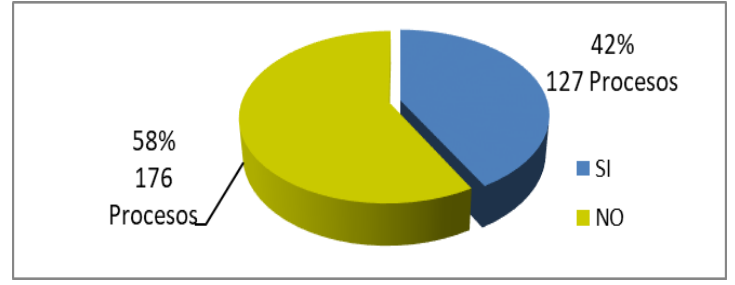

De la gráfica No. 11 se concluye que de los 303 procesos condenatorios de reparación directa de las jurisdicciones ya señaladas entre los años 2011 hasta el 2018, en que se convocó a audiencia de conciliación, en el 58\% de los casos, esto es 176 procesos, no hubo ánimo conciliatorio, y en el $42 \%$ de los casos, esto es 127 procesos, sí hubo ánimo conciliatorio.

Gráfica no. 12. Cuantía condenas objeto de conciliación

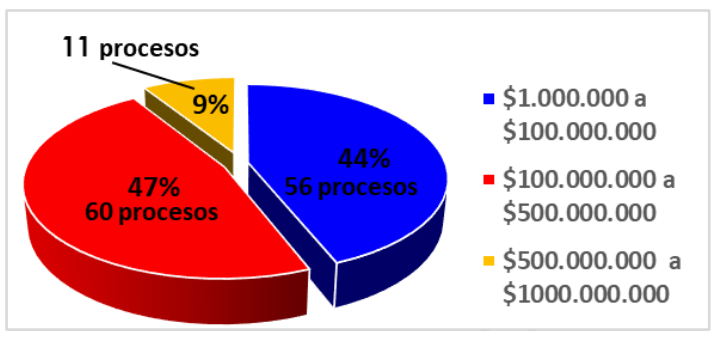

En la presente gráfica se observa que de los 127 procesos condenatorios de reparación directa de la jurisdicción contencioso-administrativa de Antioquia, Valle del cauca, Bolívar y Cundinamarca desde el año 2011 hasta el 2018, que fueron objeto de acuerdo conciliatorio, el monto de la cuantía de la condena en 56 procesos, equivalentes a un $44 \%$, osciló entre $\$ 1.000 .000$ a $\$ 100.000 .000$. En 60 procesos, equivalentes a un $47 \%$, la condena osciló entre $\$ 100.000 .000$ a $\$ 500.000 .000$. Finalmente, en 11 procesos, equivalentes a un 9\%, la cuantía de la condena osciló entre \$500.000.000 y 1000.000.000.

Gráfica no. 13. Cuantía de los acuerdos de conciliación

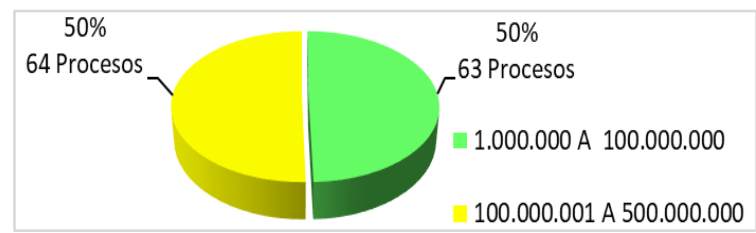

De esta gráfica se concluye que de los 127 fallos condenatorios que fueron proferidos entre el año 2011 y 2018 en las jurisdicciones objeto de estudio, y que fueron objeto de acuerdo conciliatorio, el monto de la cuantía del acuerdo de conciliación en 63 procesos, equivalentes a un $50 \%$, osciló entre $\$ 1.000 .000$ y $\$ 100.000 .000$, y en 64 procesos, equivalentes a un $50 \%$ de casos, la condena osciló entre $\$ 100.000 .000$ y $\$ 500.000 .000$.

Gráfica no. 14. Cuantía total condena procesos apelados $(\$ 113.213 .440 .630)$

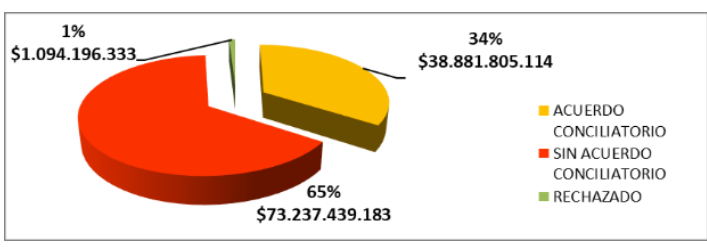

Se colige que el total de la sumatoria de la cuantía de las condenas impuestas por el juez de primera instancia en los 303 procesos condenatorios de reparación directa de la jurisdicción contenciosa administrativa de Antioquia, Valle del Cauca, Bolívar y Cundinamarca, entre los años 2011 y 2018, corresponde a $\$ 113.213 .440 .630$. De ese valor, \$73.237.439.183; es decir, el $65 \%$ del valor total de la cuantía corresponde a los procesos donde no se logró un acuerdo conciliatorio. $\$ 38.881 .805 .114$; es decir, el 34\% del valor total de la cuantía, corresponde a los 127 procesos donde hubo acuerdo conciliatorio; y \$1.094.196.333; es decir, el $1 \%$ del valor total de la cuantía, corresponde a 21 procesos donde se rechazó (18 casos) y desistió (3 casos) el recurso de apelación.

Gráfica no. 15. Análisis económico de las condenas conciliadas $\mathbf{( \$ 3 8 . 8 8 1 . 8 0 5 . 1 1 4})$

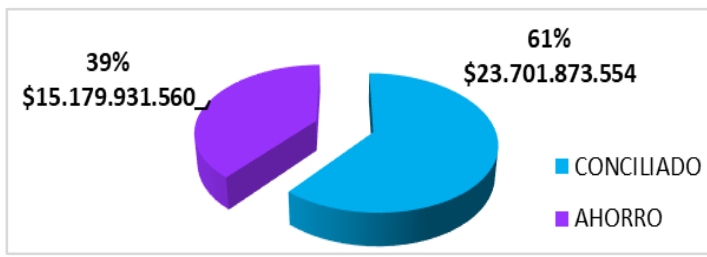

En la gráfica No. 15 se observa que el total de la sumatoria de la cuantía de las condenas impuestas por el juez de primera instancia en los 127 procesos condenatorios de reparación directa de las jurisdicciones contencioso-administrativas objeto de estudio entre los años 2011 y 2018, que lograron un acuerdo de conciliación, corresponde a $\$ 38.881 .805 .114$. El $61 \%$ de ese valor, que equivale a $\$ 23.701 .873 .554$, corresponde a la 
sumatoria de la cuantía del acuerdo de conciliación. El 39\% restante, que equivale a $\$ 15.179 .931 .560$, es el valor correspondiente a la resta entre la sumatoria de la condena que había impuesto el juez en la sentencia (\$38.881.805.114), y la sumatoria de lo que pactaron las partes en el acuerdo (\$23.701.873.554), que al final corresponde al ahorro del erario.

\subsection{Discusión de resultados}

Analizados los resultados obtenidos con los instrumentos de recolección de datos de las sentencias que comprendían la audiencia de conciliación obligatoria en cada una de las Jurisdicciones Contenciosas Administrativas en los departamentos de Antioquia, Bolívar, Cundinamarca y Valle del Cauca entre los años 2011 y 2018, en lo que atañe a la descongestión judicial, se encontró que en los diferentes Juzgados y Tribunales Administrativos objeto de estudio, la apelación fue interpuesta en la mayoría de los procesos por parte de la entidad demandada.

En total, en 205 de los 303 procesos objeto de investigación, la apelación fue hecha únicamente por el demandado. Asimismo, en 95 procesos del universo total estudiado, la apelación se interpuso por ambas partes $\mathrm{y}$, tan solo en 3 casos, el demandante fue el único apelante. Así las cosas, se encontró que, por regla general, el demandado interpone recurso de apelación frente a la sentencia en su contra, siendo en algunas ocasiones coadyuvado por el demandante al no estar de acuerdo con la condena impuesta por no conceder la totalidad de sus pretensiones. De esta manera, la entidad demandada busca, con el recurso de apelación, la absolución de la condena impuesta o, en su defecto, una disminución en la cuantía en la segunda instancia.

En cuanto a la admisión del recurso de apelación frente a la sentencia que declaró la responsabilidad estatal, 282 de estos fueron admitidos, ya que fueron sustentados dentro del término. En contraposición, 18 de estos recursos fueron rechazados por diferentes causales, siendo, la más común, la inasistencia del apelante a la audiencia de conciliación (13 procesos), seguido por la causal de radicación de manera extemporánea (3 procesos). Finalmente, se encuentra como motivo de rechazo la falta de sustentación del recurso en 2 procesos. Con las cifras anteriores, se evidencia una falta de diligencia por parte de los apoderados de las entidades públicas al no interponer el recurso dentro del término o no manifestar las razones en las cuales fundamentan el mismo.
Esta situación desencadena para las entidades demandadas una condena inamovible, desechando la oportunidad de ser conciliada para un eventual ahorro en términos económicos, o de ser al menos revisada por parte del juez de segunda instancia. En ese sentido, se encontró que dicha falta de diligencia conllevó a la imposibilidad de un acuerdo conciliatorio o una revocatoria de la condena, lo cual genera una inmensa preocupación respecto a las consecuencias pecuniarias, toda vez que la condena total de estos casos equivale a un valor de mil noventa y cuatro millones ciento noventa y seis mil trescientos treinta y tres pesos MCTE (\$1.094.196.333).

En los 282 procesos condenatorios en los cuales se citó a audiencia de conciliación, se halló que en cuanto a la asistencia a dicha audiencia por parte del demandado, demandante y el ministerio público, la parte que tuvo mayor comparecencia fue la parte demandada con un total de 256 audiencias. En contraste, en solo 249 procesos asistió la parte demandante, lo cual desencadenó que en muchos casos se declarara fallida esta audiencia por la no comparecencia de alguna de las partes, demostrando así que el interés principal recae en las entidades públicas.

Ahora bien, con relación al desarrollo de estas 249 audiencias de conciliación que fueron debidamente celebradas, se encontró nuevamente que la parte con mayor ánimo conciliatorio fue la demandada, presentando intención de conciliar en 160 casos, lo cual se correlaciona con las entidades públicas que en su mayoría (149 entidades) contaban con un concepto del comité de conciliación favorable o parcialmente favorable. Por el contrario, en tan solo 129 casos, la parte demandante tenía ánimo conciliatorio. De esta manera, se demostró la estrecha relación que tiene el Comité de Conciliación con la realización exitosa de la audiencia de conciliación, siendo un órgano no solo asesor sino decisivo, que con un análisis objetivo de la situación puede evitar cuantiosas condenas.

Finalmente, gracias a los datos analizados anteriormente, se halló que únicamente en 127 de las 303 audiencias de conciliación que fueron debidamente convocadas, hubo acuerdo conciliatorio. Es decir, en 176 de estas audiencias obligatorias no hubo acuerdo conciliatorio. Con este resultado, se podría indicar que la Audiencia de Conciliación obligatoria tratada en los artículos 70 de la Ley 1395 de 2010 y el inciso $4^{\circ}$ del artículo 192 de la Ley 1437 de 2011 dentro los procesos de 
Reparación Directa en la Jurisdicción Contenciosa Administrativa de los departamentos Antioquia, Bolívar, Cundinamarca y Valle Del Cauca entre los años 2011 y 2018, sí ha resultado efectiva como mecanismo de descongestión judicial, pues si bien no se logró un acuerdo conciliatorio en el $100 \%$ de los procesos, sí se logró en el $42 \%$ de los casos, lo que hace que esta audiencia represente un medio valioso de descongestión.

De igual forma, ante la estrecha diferencia de las anteriores cifras, se puede indicar que esta audiencia además es pertinente como mecanismo de protección del erario, toda vez que de los 127 acuerdos conciliatorios logrados en los procesos de reparación directa se halló que existió un ahorro de quince mil ciento setenta y nueve millones novecientos treinta y un mil quinientos sesenta pesos MCTE (\$15.179.931.560), pues las condenas objeto de conciliación oscilaban en treinta y ocho mil ochocientos ochenta y un millones ochocientos cinco mil ciento catorce pesos MCTE (\$38.881.805.114) y fueron finalmente conciliadas en un total de veintitrés mil setecientos un millones ochocientos setenta y tres mil quinientos cincuenta y cuatro pesos MCTE (\$23.701.873.554).

\section{CONCLUSIONES}

En cuanto a la respuesta de la pregunta objeto de investigación, sobre si ¿Ha sido pertinente, como medida de descongestión judicial, la audiencia de conciliación obligatoria de que tratan los artículos 70 de la Ley 1395 de 2010 y el inciso $4^{\circ}$ del artículo 192 de la Ley 1437 de 2011 en la Jurisdicción Contenciosa Administrativa de los departamentos Antioquia, Bolívar, Cundinamarca y Valle del Cauca entre los años 2011 al 2018 dentro los procesos de Reparación Directa?, se ha encontrado que efectivamente ha sido pertinente como mecanismo de descongestión judicial, toda vez que de los 303 procesos de reparación directa condenatorios que fueron apelados, 127 condenas fueron conciliadas, es decir, el $42 \%$ de ellas, generando que solo 176 procesos continuaran su trámite judicial en la segunda instancia. Entonces, si bien la cantidad de acuerdos conciliatorios no alcanzó la mayoría de los procesos apelados, sí representa un importante número que implica menos represamiento en los despachos judiciales como Tribunales y Sección tercera del Consejo de Estado.

Así las cosas, la audiencia de conciliación obligatoria de que tratan los artículos 70 de la Ley 1395 de 2010 y el inciso $4^{\circ}$ del artículo 192 de la Ley 1437 de 2011 tuvo un impacto positivo en materia de descongestión judicial en el periodo estudiado, ya que fueron muchos los procesos terminados al lograrse un acuerdo conciliatorio.

Igualmente, se pudo determinar que la principal causa para que el anterior resultado no fuera mayor, fue la falta de ánimo conciliatorio por parte de los demandantes, debido a la no aceptación de la propuesta presentada por la entidad demandada como fórmula de arreglo, que en la mayoría de las ocasiones proponía un pago de hasta el $80 \%$ de la condena. En contraposición, el factor preponderante para el ánimo conciliatorio de los entes demandados fue el concepto favorable o parcialmente favorable de los comités de conciliación de las entidades, siendo estos órganos colegiados decisivos en el éxito de una conciliación.

Adicionalmente, otro factor que llevó a que esta medida, como mecanismo de descongestión judicial, no tuviera un mayor porcentaje de éxito, fue la negligencia del apoderado judicial de la entidad apelante al no comparecer en 13 audiencias de conciliación, declarándose así desierto el recurso de apelación. Así también, en 3 procesos el recurso fue rechazado por ser radicado de manera extemporánea y en 2 procesos el apelante no sustentó el recurso, lo cual cerró la posibilidad de un acuerdo conciliatorio por el valor de las condenas que ascendían a mil noventa y cuatro millones ciento noventa y seis mil trescientos treinta y tres pesos MCTE (\$1.094.196.333), o en su defecto, una revisión de segunda instancia.

Finalmente, se estableció como beneficio jurídico y económico de los 127 acuerdos conciliatorios que se concertaron en las audiencias de conciliación obligatorias de que tratan los artículos 70 de la Ley 1395 de 2010 y el inciso $4^{\circ}$ del artículo 192 de la Ley 1437 de 2011 en la Jurisdicción Contenciosa Administrativa de los departamentos Antioquia, Bolívar, Cundinamarca y Valle del Cauca entre los años 2011 y 2018 dentro los procesos de Reparación Directa, el gran impacto fiscal que generan, toda vez que la nación logró un ahorro del $39 \%$ de quince mil ciento setenta y nueve millones novecientos treinta y un mil quinientos sesenta pesos MCTE (\$15.179.931.560).

\section{RECOMENDACIONES}

Con el indeclinable propósito de aportar soluciones efectivas para incrementar la eficacia de la conciliación judicial obligatoria, el grupo de investigación CONCIENCIA JURÍDICA, de forma respetuosa, pone en consideración algunas alternativas que considera viables y apropiadas. 
En primer lugar, es pertinente que la ley consagre una sanción pecuniaria o disciplinaria para el apoderado judicial que no asista a la audiencia de conciliación, debido a que actualmente la ley únicamente prevé la declaratoria desierta del recurso si el apoderado ausente tiene la calidad de apelante. De esta manera, los abogados se verían motivados a participar en la audiencia para suplir un interés personal, que consistiría en evitar la posible multa o sanción sobre su nombre.

Por otro lado, debido a que los colombianos han adoptado la tradición litigiosa que comprende la "judicialización de los conflictos", y han dejado atrás otras alternativas adecuadas para resolver divergencias jurídicas, se hace menester la creación de una política pública que contemple la prestación de capacitaciones gratuitas dirigidas a jueces, abogados litigantes, asesores jurídicos de entidades públicas y a la ciudadanía en general sobre los beneficios de la conciliación; también, es menester formar a los intervinientes de la audiencia en competencias de negociación y resolución.

A su vez, se hace imperioso que todas las entidades públicas cuenten con un comité de conciliación, puesto que este es el encargado de cuantificar el valor conciliable que se estipula posteriormente en el acta, y de brindar un direccionamiento adecuado que proteja los intereses pecuniarios de la entidad a la que pertenecen. No obstante, también es menester que se brinden capacitaciones y/o seminarios sobre conciliación a sus miembros de manera permanente.

De igual manera, se considera que no es conveniente que el juez de primera instancia sea quien presida el tipo de audiencia de conciliación, debido a que él, por haber dictado sentencia condenatoria y haber conocido el proceso judicial de primera mano, no tendrá una visión imparcial y objetiva de la situación; por tanto, la audiencia debería ser dirigida por el jurisconsulto de segunda instancia, antes de conocer de fondo el caso.

Por último, en el desarrollo de la audiencia de conciliación, el juez debería tener mayor participación; un papel más proactivo. Es decir, en el caso en el que la propuesta diseñada por el comité de conciliación de la entidad no sea adecuada para la parte demandante, el juez no debería dar por finalizada la audiencia por considerarla fallida; él podría tomar en cuenta la fórmula de arreglo de la parte demandante y, con base en ella, podría generar sus propias iniciativas de arreglo, que serían allegadas al comité de conciliación para un posterior análisis.

\section{REFERENCIAS BIBLIOGRÁFICAS}

I. CNC. (s.f.) Centro Nacional de Conciliación. La Conciliación. Disponible en: http://cnc.com.co/portal/conciliacion.php

II. Confucio (550 A.C.) citado por OsorioVillegas, A. M. (2002). Conciliación: Mecanismo alternativo de solución de conflictos por excelencia. Trabajo de grado, Pontificia Universidad Javeriana. Recuperado de https://www.javeriana.edu.co/biblos/tesis/derecho/ dere4/Tesis-15.pdf

III. MINJUSTICIA, (2015). Conciliación en Equidad. Normatividad, jurisprudencia, conceptos y concordancias. Segunda edición. Bogotá. Disponible

en:

http://www.minjusticia.gov.co/InvSocioJuridica/D boRegistros/GetPdf?fileName=\%7B1EECEF9C1E8C-4506-B1C3-EE18B2D25B7D\%7D.pdf

IV. Osorio-Villegas, A. M. (2002). Conciliación: Mecanismo alternativo de solución de conflictos por excelencia. Trabajo de grado, Pontificia Universidad Javeriana. Recuperado de https://www.javeriana.edu.co/biblos/tesis/derecho/ dere4/Tesis-15.pdf

V. Peña-Guevara, A., Polo-García, C., y Solano-Vargas, D. (s.f.). Conciliación extrajudicial, un análisis a su aplicación desde un punto de vista jurídico. Pontificia Universidad Javeriana. Facultad de Ciencias Jurídicas. Disponible en: https://www.javeriana.edu.co/biblos/tesis/derecho/ dere5/TESIS23.pdf

VI. Peña-Sandoval, H. (2014). 20 años del sistema nacional de conciliación en Colombia: Breve análisis normativo. Bogotá. 2014, 2. Disponible en:

http://babel.banrepcultural.org/cdm/ref/collection/ p17054coll23/id/697

VII. Sánchez, R. (2014). Indicadores Doing Business como tecnología de gobernanza global sobre la administración de justicia en Colombia. Precedente, 5. Cali, Colombia. Disponible en: https://www.researchgate.net/publication/2835899 81_Indicadores_Doing_Business como tecnologi a_de_gobernanza_global_sobre_la_administracio $\underline{n}$ de justicia en Colombia

VIII. Torres-Calderón, L. A. (2016). Reflexiones sobre la congestión judicial en la Jurisdicción de lo contencioso-administrativo colombiana. Universidad de la Sabana. Revista

Dikaion, (11). Disponible en: http://dikaion.unisabana.edu.co/index.php/dikaion /article/view/317/459

IX. Toscano-López, B., y Ortiz-Ortiz, C. (2012). La eficacia de la audiencia del artículo 70 
de la ley 1395 de 2010. Universidad Militar Nueva

Granada. Recuperado de:

https://repository.unimilitar.edu.co/bitstream/hand

le/10654/9235/ToscanoLopezBrunoEdwin2012.pd

$\underline{\mathrm{f} \text { ?sequence }=2 \& \text { is Allowed }=\mathrm{y}}$

REFERENCIAS JURISPRUDENCIALES

X. CConst, C-902/2008. M.P. Pinilla, N.

Disponible

en:

http://www.corteconstitucional.gov.co/relatoria/20

$\underline{\text { 08/C-902-08.htm }}$

\section{REFERENCIAS NORMATIVAS}

XI. Constitución política de Colombia. Const, 1991. Art 116; 228

XII. L. 1395/2010. Art. 70. Por la cual se adoptan medidas en materia de descongestión judicial.

XIII. L. 1437/2011 Art. 192, Inc. 4. Por la cual se expide el Código de Procedimiento Administrativo y de lo Contencioso Administrativo.

XIV. L. 23/1991. Por medio de la cual se crean mecanismos para descongestionar los Despachos Judiciales, y se dictan otras disposiciones.

XV. L. 640/2001. Por la cual se modifican normas relativas a la conciliación y se dictan otras disposiciones. 